\title{
TEMPOS MODERNOS, NOVOS PARTOS E NOVAS PARTEIRAS: O PARTO NO JAPÃO DE 1868 AOS ANOS 1930
}

\author{
AYA HOMEI \\ University of Manchester
}

\begin{abstract}
Resumo: As shin-sanba, ou 'novas parteiras' medicalizadas, que apareceram durante o período Meiji (1868-1912) no Japão, parecem ter, aos olhos atuais, substituído rapidamente e sem conflito as 'velhas parteiras' (kyû-sanba) e as cada vez mais criminalizadas 'parteiras não licenciadas' (mumenkyo-sanba), enquanto a profissão de parteira foi se desenvolvendo progressivamente como profissão médica moderna. Este artigo sugere que a história das parteiras na era moderna foi mais complexa do que aquilo que se imagina atualmente. Primeiro, o surgimento e a prosperidade das shin-sanba estiveram intrinsecamente ligados às contingências do Japão moderno e ao inter-relacionamento de vários grupos de atores históricos - autoridades da higiene, sankai (ginecologistas-obstetras), outras parteiras e 'clientes'. Segundo, ao longo da era moderna, as shin-sanba não substituíram outros tipos de parteiras; na verdade, os diferentes tipos co-existiram. Por fim, a existência e o status das parteiras dependeram em grande parte de um mercado de serviços de saúde marcado pelo laissezfaire, e as realidades desse mercado muitas vezes contradiziam a retórica médica que favorecia as shin-sanba em relação a outros tipos de parteiras.
\end{abstract}

Palavras-chave: parteiras, Japão, período Meiji.

\section{Parto e atendimento ao parto no Japão antes da era moderna}

O fenômeno biológico do parto acontece em todo o planeta desde que os seres humanos começaram a habitá-lo, mas atualmente sabemos que as práticas do nascimento são cultural, histórica e geograficamente específicas. ${ }^{1}$ O parto no Japão antigo, por exemplo, era totalmente diferente dos procedimentos atuais, tecnologicamente sofisticados, do Primeiro Mundo. ${ }^{2}$ Para os antigos japoneses, 0 parto era um acontecimento perigoso, extraordinário, durante o qual a mulher e a criança flutuavam entre o mundo dos mortos e o dos vivos. Por isso uma mulher dava à luz em uma sala especial, que separava metaforicamente o parto dos

\footnotetext{
Copyright (c) 2002 by Revista Estudos Feministas

${ }^{1}$ Artigo produzido em maio de 2002.

${ }^{2}$ Sobre a história do conceito e da prática do parto no Japão, ver, por exemplo, Keikichi KUNIMOTO, 1997; Taku SHINMURA, 1996; Emiko MATSUOKA, 1985; e AllKUKAI, 1977.
} 
acontecimentos da vida cotidiana. ${ }^{3}$ Nessa sala, a mulher paria usando uma roupa branca, a mesma vestimenta normalmente colocada nos mortos, e deixava os cabelos soltos. Ali, uma parteira experiente, chamada koshidaki ("cintura envolvente, aconchegante"), assistia a parturiente, que normalmente abraçava sua cintura. ${ }^{4}$ Só quando havia uma complicação era chamado um profissional homem, um nyo-i (médico especializado em doenças de mulheres), que prescrevia medicamentos.

Já no período Edo (1603-1867) a cultura do parto era suis generis. Naquele tempo, o Japão testemunhou o surgimento do estudo 'científico' do parto, influenciado pela koihô (escola antiga de medicina) e pela rangaku (escola de 'estudos holandeses', oficialmente reconhecida, em que a medicina ocidental teve um papel central), quando foi introduzido um olhar empírico à concepção, à gravidez e ao parto. ${ }^{5}$ Com base nisso, os sankai (ginecologistas-obstetras) homens começaram a aparecer, e os da Escola Kagawa de Obstetrícia, em particular, tornaram-se proeminentes. ${ }^{6} \mathrm{O}$ fundador da escola, Kagawa Gen'etsu (1700-1777), ficou famoso com sua kaitenjutu, 'técnica rotativa', com a qual tirava o bebê natimorto do útero com um gancho. ${ }^{7}$

No início do século XIX, quando os sankai (homens) já haviam assegurado sua perícia no trato das complicações do parto, alguns deles começaram a denunciar parteiras abertamente, assim como acontecera na Europa no século anterior. ${ }^{8}$ As razões variavam, porém a mais plausível era a de que os sankai queriam dominar todos os aspectos do atendimento ao parto, incluindo as tarefas consideradas exclusivas das parteiras. ${ }^{9}$

\footnotetext{
${ }^{3}$ Ver SHINMURA, 1996, p. 166. Ver também Setsuko Nishikawa, 1992, p. 30. Alguns dispositivos também eram usados para, metaforicamente, 'purificar' o parto, inevitavelmente impuro. Para o conceito de impureza, ver Emiko NAMIHIRA, 1985.

${ }^{4}$ SHINMURA, 1996. Ver também Kunimoto, 1997.

${ }^{5}$ SHINMURA, 1996. Para a história geral da cena médica no Japão da era Edo, ver John BOWERZ, 1980; e BOWERZ, 1970.

- O termo japonês sankai já era usado no século XVIII. Ao contrário do que acontecia no Ocidente, o Japão incluía a obstetrícia entre os estudos dos nyoi (médicos de doenças de mulheres) desde o século IX, e o termo ficou associado a uma etiologia diferente daquela costumeira evocada no Ocidente pela palavra 'obstetra'. A profissão no Japão teve por modelo a obstetrícia alemã, e o termo sankai é de fato mais próximo ao alemão Geburtshilfe, de sentido mais amplo, do que do termo inglês obstetrician.

O termo japonês, inclusive, pode ser visto como a união de três caracteres chineses (san = parto; $k a=$ disciplina, departamento, campo acadêmico; e $i$ = médico), significando 'médico dos estudos do parto', ou 'médico especialista em partos'. Parece-me que o termo [inglês] mais adequado para o sankai do século XIX seria 'ginecologistaobstetra', mas, em respeito a toda essa amplitude semântica, prefiro o termo japonês a qualquer tentativa de adaptá-lo ao inglês.

[A decisão da autora valeu também em relação ao português, principalmente em função da distinção profissional, válida no Brasil, entre obstetrícia e ginecologia (Nota do Tradutor).]

${ }^{7}$ Masakiyo OGATA, 1919.

${ }^{8}$ Para o caso inglês, o título clássico é Jean DONNISON, 1977. Para o caso americano, ver Judy Barreft LITOFF, 1978; e Bárbara EHRENREICH e Deirdre ENGLISH, 1973. Para o caso europeu, ver Hilary MARLAND e Anne RAFFERTY,1997. O ataque às parteiras no Japão no período Edo pode estar ligado ao status da parteira como uma eta, pessoa dos estratos sociais mais baixos do sistema de castas da época, considerada como alguém que lidava com impurezas. Ver Brigitte STEGER, 1994.

${ }^{9}$ Havia, é claro, uma pequena minoria de médicos que reconheciam o papel da parteira como uma assistente importante para o obstetra, e que, portanto, tentaram reformar a profissão de parteira. Um livro representativo sobre isso é o Zaba Hikken (1830), de Hirano. Além dos ensinamentos práticos, o Zaba Hikken ensinava a moral e a responsabilidade profissionais da sanba, de modo que a sanba podia desenvolver seu papel como uma assistente respeitável para obstetras.
} 
Apesar da tentativa de alguns sankai de invadir a esfera das parteiras, as pessoas os chamavam apenas em casos de emergência. Assim, no final do período Edo a parteira ainda se mantinha como a principal figura no atendimento ao parto, na maioria das regiões. O trabalho da parteira ia além da mera assistência. As pessoas costumavam consultá-la sobre assuntos da reprodução em geral, incluindo interrupção de gravidez. ${ }^{10} \mathrm{Em}$ algumas regiões, as parteiras eram até convidadas para rituais envolvendo ritos de passagem para bebês. ${ }^{11}$

Além desses peritos em atendimento ao parto, ou seja, parteiras e sankai, vizinhas e parentes do sexo feminino tinham também uma participação importante. Os homens eram geralmente desencorajados a participar, a não ser quando as mulheres tinham muitas dificuldades de lidar sozinhas com uma determinada situação. Nesse caso, o marido podia entrar, e as mulheres pediam a ele que segurasse a esposa para facilitar o parto. Além disso, a participação do homem era encorajada mais nas cidades do que no meio rural, porque as famílias urbanas estavam cada vez mais reduzidas ao núcleo familiar, o que acarretava uma falta de mulheres acostumadas a auxiliar nos partos. ${ }^{12}$

\section{Novo governo, novos sankai, novas parteiras ${ }^{13}$}

Em 1868, depois da Restauração, assumiu o governo Meiji. O novo regime estava determinado a reestruturar e modernizar todos os aspectos da vida no país. Na medicina, a modernização significava a adoção convicta da medicina alemã, o que o governo anunciou oficialmente no primeiro ano do período Meiji (1868-1912). A partir de então, muitos médicos, incluindo os sankai, saíram do país para estudar e apreender a medicina alemã.

Ao mesmo tempo, o governo Meiji enfrentava outro problema urgente: o combate a doenças infecciosas. ${ }^{14} \mathrm{~A}$ epidemia de cólera, particularmente, devastava o país desde 1870, e as autoridades a consideravam como o maior obstáculo a uma modernização rápida e bem-sucedida. Para combater uma epidemia tão violenta, o governo criou o Departamento da Higiene, vinculado ao Ministério do Interior, em 1876, além de escritórios regionais. Juntos, Departamento e escritórios regionais desenvolveram um programa muito bem estruturado em nível nacional. Esses escritórios eram auxiliados por organizações de consultoria que normalmente contavam com médicos proeminentes. As parteiras foram logo enquadradas nesse programa, sendo em primeiro lugar exigido que se tornassem, elas mesmas, higiênicas, e depois que disseminassem a noção e a prática do parto higiênico, a fim de estender a modernização do país à população em geral. ${ }^{15}$

\footnotetext{
${ }^{10}$ Sobre aborto e infanticídio no período Edo, ver Mikako SAWAYAMA, 1999; e William LAFLEUR, 1992. Durante a era Meiji, o governo criminalizou o aborto em 1880. Para historiografias recentes, ver, por exemplo, Yuki FUJIME, 1998; e Shoko ISHIZAKI, 1997.

${ }^{11}$ Kennosuke NEGISHI, 1991.

12 SHINMURA, 1996. Há evidências de que a ajuda do marido era real em pequenas cidades mais afastadas de Shikoku, mesmo na era moderna. Ver Norico YOSHIMURA, 1996.

${ }^{13}$ Para a historiografia das parteiras modernas no Japão, ver Julie ROUSSEAU, 1998; FUJIME, 1993; Hiroko HASEGAWA, 1993; Emiko OCHIAI, 1990; e Mugiko NISHIKAWA, 1989. Há que se considerar também que enfermeiras e parteiras japonesas, durante a era moderna, curiosamente divergiam. Tal comparação entre a parteira moderna e a enfermeira moderna no Japão será crucial para pesquisas futuras, pois vai iluminar questões referentes à profissionlização de cada uma. Sobre a enfermeira japonesa moderna, ver Aya TAKAHASHI, 1999; e Michiko KAMEYAMA, 1990.

14 IINKAI, 1988.

${ }^{15}$ STEGER, 1994.
} 


\section{Regulamentação da profissão de parteira ${ }^{16}$}

Junto com as medidas acima mencionadas, o governo Meiji quis modernizar a profissão de parteira como um todo. Em 1868, as autoridades lançaram uma medida que proibia as parteiras de fazerem aborto e de comercializar medicamentos. Em 1874, 0 ministério que cuidava da administração da prática da medicina promulgou o Isei, o 'Sistema Médico', em três cidades, Kioto, Osaka e Tóquio. O Isei estabelecia que as parteiras tinham de ser mulheres com mais de 40 anos, familiarizadas com os conhecimentos modernos da medicina da mulher e da criança. Exigia também uma licença para o exercício profissional da parteira de âmbito local, concedida após uma prova prática assistida por um sankai. Logo outras prefeituras adotaram o Isei, e na década de 1890 quase todas as prefeituras tinhas suas próprias regulamentações locais. Então, em 1899, essas regulamentações foram resumidas no Decreto das Parteiras, de âmbito nacional. O Decreto estabelecia que as parteiras tinham de ser treinadas em uma escola específica, ter mais de 20 anos e estar familiarizadas com os modernos conhecimentos da obstetrícia.

\section{A educação das parteiras}

Atendendo ao Isei de 1874, instituições médicas iniciaram a formação profissional de parteiras. Já em 1875, o Hospital Municipal de Osaka iniciou palestras suplementares para alunas do curso de partos. Em 1876 e 1879, respectivamente, o Hospital Municipal de Tóquio e a Escola de Medicina de Niigata fizeram o mesmo. Mas, na realidade, assumir um sistema tão radicalmente novo não foi fácil. Muitas alunas (incluindo parteiras já em atividade) eram casadas, tinham filhos e estavam mais preocupadas com os afazeres cotidianos do que com a formação. ${ }^{17}$ Além disso, o transporte público inadequado tornava difíceis a locomoção e o acesso à escola. Por esses motivos, a educação e os exames exigidos das aspirantes a parteira pelos regulamentos locais acabaram virando uma questão meramente formal.

Na década de 1890, no entanto, surgiu uma nova tendência. Alguns sankai da elite, politicamente influentes, haviam voltado da Alemanha e defendiam a formação de shin-sanba, 'novas parteiras', pois precisavam de assistentes para seus futuros trabalhos em hospitais. Hamada Gentatsu voltou a Tóquio em 1888. Convencido da necessidade de parteiras modernas também no Japão, Hamada entrou com uma petição solicitando ao governo o estabelecimento de uma escola pública para formação de parteiras. As autoridades referendaram a petição, e em 1890 a escola era inaugurada na Faculdade de Medicina da Universidade de Tóquio. Outro sankai, Ogata Masakiyo, voltou a Osaka, depois de três anos de estudo em várias cidades da Alemanha e de outros países europeus, e em 1892 abriu a Escola Ogata de Parturição. Diferentes de suas predecessoras da década de 1870, essas novas escolas urbanas aceitaram muitas jovens recém-saídas da educação primária, criando assim uma regra efetiva para a qualificação de parteiras modernas, que o Decreto de 1899 incorporou.

Em 1910, o Ministério do Interior modificou o Decreto. De acordo com a nova versão, as alunas formadas por escolas credenciadas (incluindo a da Universidade de Tóquio e a de Ogata) poderiam obter a licença sem exame. A partir de então, o número total de shinsanba disparou (veja tabela ao final do texto). Aquelas que eram normalmente chamadas parteiras e passaram pela educação formal tornaram-se shin-sanba, ou seiyo sanba,

\footnotetext{
${ }^{16}$ Akira SUGAYA, 1976, p. 295-304. Curiosamente, se as regulamentações sobre parteiras no Japão começaram a aparecer já no início do período Meiji, a enfermagem só seria regulamentada em 1904.

17 YOSHIMURA, 1996, p. 124.
} 
'parteiras ocidentais', em oposição a kyû-sanba, as 'velhas parteiras', que continuaram a praticar como no período anterior. As pessoas passaram a associar as jovens shin-sanba, 'ocidentais' (isto é, 'científicas') e acima de tudo 'novas' parteiras com a modernidade, enquanto as kyû-sanba eram identificadas com o 'velho', o 'tradicional', isto é, o 'antimoderno'. E, através do processo de criação dessa polarização, foi-se desenvolvendo um conceito do sistema de parto da era moderna.

\section{'Novas parteiras', 'velhas parteiras' e 'parteiras não licenciadas'}

Além dos fatores que atrapalharam a popularização das shin-sanba, houve ainda outro obstáculo. Onde a cultura do parto domiciliar, típico do período Meiji, predominava, o trabalho das shin-sanba era especialmente visível, e as pessoas comuns o consideravam radicalmente 'novo'. Nas casas onde atendiam, as shin-sanba usavam instrumentos médicos tidos como esotéricos. Bem à vontade, lavavam e desinfetavam com ácido carbólico, algo completamente estranho para pessoas leigas. Além disso - e o pior de tudo - pediam à família para chamar um médico sankai, que cobrava caro, para complicações consideradas menores. As pessoas não estavam acostumadas ao parto medicalizado que as shin-sanba, estranhas, caras e dogmáticas, faziam. Preferiam as kyû-sanba das comunidades, com mais disposição para escutá-las. Assim, principalmente nas províncias, as kyû-sanba permaneceram como principais assistentes dos partos até a década de $1930 .{ }^{18}$

Nesse meio tempo, enquanto o parto obstétrico ganhava espaço, as parteiras adeptas do parto moderno começaram a acusar as kyû-sanba de adotar procedimentos antimodernos e perigosos. Enquanto liderava sua escola de parturição, Ogata lançou um jornal mensal, o Josan no Shiori (Guia do Parto) em 1896, dirigido principalmente para as parteiras da periferia e do meio rural, que não podiam freqüentar seu curso, com o objetivo de ensinar as últimas tendências no atendimento ao parto. Curiosamente, nas duas primeiras décadas de circulação - coincidentemente no período entre o início da produção das shin-sanba pelos sankai e a superação do número de kyû-sanba pelo de shin-sanba - o Josan no Shiori manteve uma seção de notícias que acusava as kyû-sanba de procedimentos inadequados. Em abril de 1899, por exemplo, o Josan no Shiori noticiou um caso em que uma mãe morreu subitamente de hemorragia, apenas uma hora depois do parto. ${ }^{19}$ A notícia dizia que uma 'parteira formada' (isto é, uma shin-sanba) teria podido salvar a mulher, e lamentava a indicação de uma 'parteira amadora' (kyû-sanba), afirmando que esta tinha sido diretamente responsável pelo incidente. Do mesmo modo, o sankai Kawahara Shinzo escreveu um pequeno artigo sobre o "Perigo das velhas parteiras" em uma edição comemorativa de outubro de 1912. ${ }^{20}$ Kawahara conta que uma kyû-sanba veio lhe pedir insistentemente um medicamento que acelerasse o trabalho de parto, sem Ihe informar o motivo. Desconfiado, ele mandou sua assistente (provavelmente uma shinsanba) à cena do parto. A assistente voltou e lhe contou que o bebê estava de fato mal posicionado. Kawahara então teve que ir retirá-lo com fórceps. O bebê estava num estado sincópico perigoso, mas, graças ao método de ressurreição de Ogata, Kawahara conseguiu trazê-lo à vida.

Simultaneamente o jornal publicava, nessa seção, notícias sobre as mumenkyosanba, ou 'parteiras não licenciadas'. Sob o título "Punição a uma parteira má", a edição

\footnotetext{
${ }^{18}$ NEGISHI, 1991, p. 328.

19 "Bunbenji Shukketsu ni yoru Shibo".

${ }^{20}$ Kawahara, 1912.
} 
de abril de 1900 informava que uma parteira em Kisarazu foi condenada a nove anos de prisão por ter sufocado o bebê até a morte, enterrando-o perto do banheiro da família, do lado de fora da casa. ${ }^{21} \mathrm{O}$ artigo conclui: "trata-se de um acontecimento estarrecedor. $\mathrm{O}$ ato da parteira não licenciada é comparável à crueldade de um ogro". ${ }^{22}$

A mesma seção do jornal serviu ainda para criar uma imagem santificada das shinsanba. A edição de setembro de 1899, por exemplo, trouxe a notícia da parteira Hayashi Teru, licenciada pelo Ministério do Interior, que pagou ela mesma pelo serviço de um sankai, chamado em nome de uma família pobre em Tóquio, a fim de oferecer a solução obstétrica correta para o caso de um bebê mal posicionado. ${ }^{23}$

Desde o Decreto de 1899, foi exigido de todas as parteiras que obtivessem 'algum' tipo de registro e licença de uma autoridade local. Sob a nova regra, as shin-sanba obtiveram a licença do Ministério do Interior depois de passar nos exames, enquanto muitas kyû-sanba, sem passar pelo treinamento formal, simplesmente registraram-se e adquiriram licenças regionais, de âmbito mais restrito ('com experiência prévia' ou 'atuação restrita à regiấo'), concedidas temporariamente (veja a tabela). Nesse novo esquema, as parteiras não registradas tornaram-se mumenkyo-sanba e foram todas criminalizadas.

Nesse contexto, o Josan no Shiori transformou as kyû-sanba em um grupo de risco e demonizou as parteiras que, embora experientes, não eram licenciadas. Isso não só ajudou a excluir da nova cultura do parto as demais parteiras, exceto as shin-sanba, como também serviu para formar uma nova hierarquia entre as parteiras. Nessa hierarquia, as shin-sanba eram consideradas as mais legítimas, as mais seguras e as mais habilidosas, seguidas logo abaixo pelas kyû-sanba, tidas como menos legítimas e mais perigosas. Finalmente, abaixo destas vinham as mumenkyo-sanba, que fariam qualquer coisa por dinheiro, incluindo práticas criminosas como aborto e infanticídio.

E aqui dever ser observado que a shin-sanba era, junto com o sankai, uma participante ativa no estabelecimento da retórica que justificou e solidificou essa nova hierarquia. Essa retórica, que os sankai modernos haviam trazido da Alemanha, era baseada na divisão profissional do trabalho em que a mulher shin-sanba cuidava de partos 'normais' enquanto o homem sankai solucionava os 'anormais'. A base dessa retórica aparentemente complementar da divisão do trabalho, de forma alguma, era a mesma para as profissões envolvidas. Mas, apesar da desigualdade, as shin-sanba voluntariamente aderiram a ela, porque ao fazê-lo, de mãos dadas com o sankai moderno, eram capazes de assegurar seu próprio nicho profissional.

\section{Mais oportunidades para as 'novas parteiras'}

Por causa dos esforços de sankai modernos, mais tarde compartilhados pelas 'novas parteiras', as shin-sanba se tornaram maioria a partir da década de 1910. O fenômeno foi muito mais visível nas áreas urbanas, onde sankai modernos como Ogata apoiaram a formação de novas parteiras. Além disso, durante esse período, as áreas urbanas ofereceram outra oportunidade à proliferação das shin-sanba. As condições de vida dos bairros pobres se tornaram objeto de discussão entre as autoridades, em parte devido ao movimento democrático do período Taisho (1912-1925) e a pressões internacionais. Até então a modernização do país era pensada sobretudo a partir da industrialização, negligenciandose assim (e normalmente sacrificando) a saúde dos trabalhadores. ${ }^{24}$ Paralelamente,

\footnotetext{
${ }^{21}$ AKUSANBA NO SHOBATSU.

${ }^{22}$ AKUSANBA NO SHOBATSU, p. 94.

${ }^{23}$ KITOKU NO SANBA.
} 
autoridades do fim do período Meiji, enquanto se preparavam para $\circ$ Congresso Internacional da Higiene em Dresden, em 1911, perceberam horrorizados que as taxas de mortalidade materna no Japão permaneciam consideravelmente altas se comparadas às de outros países 'civilizados', onde caíam rapidamente. ${ }^{25} \mathrm{O}$ governo considerou essa realidade como marco do atraso e da fragilidade do Japão como Estado nacional moderno. Assim, junto com ativistas democráticas e feministas, predominantemente de classe média, o governo adotou algumas soluções práticas. Uma delas foi a melhoria das condições de trabalho das mulheres através do estabelecimento de uma legislação específica.$^{26} \mathrm{~A}$ outra foi a instalação de um sistema especial de atenção ao parto e ao cuidado das crianças das classes baixas urbanas. Aqui o governo decidiu lançar mão das shin-sanba. Nesse esquema, algumas shin-sanba foram contratadas por clínicas públicas de parto, enquanto outras trabalharam como parteiras-enfermeiras visitadoras (junkai sanba), já que as parteiras continuavam, de qualquer modo, visitando as casas para desenvolver seu trabalho. Nos anos 1920, as junkai sanba, ou parteiras-visitadoras, podiam ser vistas não apenas em áreas urbanas, mas também em muitas regiões do Japão. ${ }^{27}$

Com isso, na época em que era fundada a Associação das Parteiras do Japão, em 1927, já havia uma base sólida sobre a qual a nova geração de shin-sanba dos anos 1930 pôde fundamentar suas reivindicações de qualificação, mesmo no interior.

\section{As 'novas parteiras' e o 'novo parto'}

Assim, essas parteiras da nova geração, nos anos 1930, puderam aplicar, com o máximo de fidelidade, o que aprenderam nas escolas de formação profissional. ${ }^{28} \mathrm{E}$ elas estavam por toda parte: faziam partos em domicílio, que ainda eram os mais comuns, além dos partos da classe média, em hospitais, e das mulheres da classe baixa nos estabelecimentos gerenciados por entidades filantrópicas. Por mais diferentes que fossem os locais dos partos, as shin-sanba normalmente monitoravam e cuidavam apenas de partos 'normais', com suas próprias técnicas e seus instrumentos de tecnologia não muito sofisticada. Eram também altamente cuidadosas com a higiene. Mas, quando aparecia qualquer complicação, antes mesmo de tentar resolvê-la por si sós, as shin-sanba imediatamente pediam ajuda aos sankai.

\section{As 'novas parteiras' rejeitadas}

A demanda social pelas shin-sanba, junto com uma educação efetiva, conferiuIhes autoridade sobre as kyû-sanba e sobre as mumenkyo-sanba. Além disso, no parto domiciliar medicalizado, a shin-sanba, expoente do conhecimento médico, exercia poder sobre os 'clientes'. Parentes, vizinhas e maridos ainda participavam, mas sempre sob o comando da shin-sanba; eles não podiam fazer nada além de confiar na shin-sanba. Do mesmo modo, as parturientes se tornaram corpos dóceis. Sem o conhecimento médico,

\footnotetext{
${ }^{24}$ Ver Sheldon GARON, 1997.

${ }^{25}$ ISHIZAKI, 2000.

${ }^{26}$ Para a historiografia sobre as trabalhadoras no Japão moderno, ver, por exemplo, Janet HUNTER, 1995; Gail Lee BERNSTEIN, 1991; Patrícia TSURUMI,1990; e KENKYUKAI, 1982. Sobre a regulamentação do trabalho industrial feminino, ver, por exemplo, Chikako KATO, 2001.

${ }^{27}$ Como exemplo, ver Atsuko YUMOTO, 1999.

${ }^{28}$ Ver NISHIKAWA, 1989. Ver também autobiografias posteriores de parteiras lançadas nos anos 1990, por exemplo, Atsuko NAKAMOTO, 1998; Sumiko

NOMOTO, 1998; Sumi NAGASAWA, 1995; e Eiko TAKEDA, 1992.
} 
durante trabalho de parto as mulheres tinham de aceitar passivamente as palavras da shin-sanba.

Entretanto, essa hipotética relação hierárquica que se instalava entre as shin-sanba e outras sanba, bem como entre as shin-sanba e seus clientes, nem sempre acontecia na prática. Um fator importante para intensificar a hierarquia era o fato de as shin-sanba, assim como outros praticantes da medicina do período moderno, serem forçadas a trabalhar em um mercado de serviços de saúde dominado pelo laissez-faire. ${ }^{29} \mathrm{Em}$ áreas urbanas, por exemplo, o número de shin-sanba aumentou durante os anos 1920, havendo muita competição entre elas. Em áreas rurais, essa tendência continuou ainda por mais uma década. ${ }^{30} \mathrm{~A}$ prosperidade do negócio das sanba dependia do quanto uma sanba fosse bem estabelecida e respeitada na comunidade em que trabalhava. Com isso, a realidade costumava trair a retórica da ordem hierárquica entre as parteiras. A formação médica anterior deveria ter tornado as shin-sanba poderosas, mas na prática muitas delas eram inábeis. Assim, principalmente nas áreas rurais, onde não havia hospitais para o ensino clínico, muitas shin-sanba, para obter a prática necessária, lançavam mão do aprendizado com outras sanba, 'menos legítimas'. Para as shin-sanba jovens e inexperientes, era necessário não só adquirir habilidades práticas mas também assegurar uma 'clientela' para a carreira futura.

O mercado médico marcado pelo laissez-faire dava poder aos 'clientes', invertendo a ordem hierárquica entre as shin-sanba e os membros da família atendida. ${ }^{3{ }^{3}}$ Por exemplo, muitos 'clientes' se recusavam a chamar um sankai quando a shin-sanba julgava isso absolutamente necessário. Um caso, relatado no Josan-no-Shiori, da shin-sanba llegami Yoneko, de Osaka, revelou que seus clientes recusaram um sankai por causa da pobreza, segundo alegou a família. ${ }^{32}$ Menos freqüentemente o motivo da recusa era o medo dos boatos na comunidade rural. A shin-sanba Takagashi Koto enfrentou um caso em que sua cliente recusou por duas vezes a orientação de lkegami porque a parturiente havia ficado grávida solteira, trabalhando como empregada em Osaka. ${ }^{33} \mathrm{O}$ pai da criança, se nem quis saber da gravidez, muito menos iria pagar os custos do parto.

\section{Conclusão}

Esse panorama da história das parteiras modernas revela vários aspectos. Primeiro, a nova cultura do parto surgiu de contingências históricas da década de 1860 . As autoridades do novo regime consideraram a existência das shin-sanba, como possíveis disseminadoras de conceitos e práticas de higiene, como um componente crucial de um país modernizado. Nesse contexto, as autoridades da higiene dos anos 1870 monitoraram a cultura do parto enquanto os médicos procuraram formar as shin-sanba segundo seu modelo. Essa tentativa inicial não foi bem-sucedida, já que havia vários obstáculos para a implementação real dessa nova cultura.

Segundo, a implantação do novo sistema foi dificultada pelo choque entre o 'velho' e o 'novo'. Embora o fornecimento ao país das shin-sanba fosse bem-sucedido, elas tinham dificuldades para disseminar o parto medicalizado, porque tentavam impor 'novos' procedimentos na esfera cultural do 'velho', isto é, do parto domiciliar.

\footnotetext{
${ }^{29}$ Sobre esse problema, ver Roy PORTER, 1989.

${ }^{30}$ ROUSSEAU, 1998.

${ }^{31}$ Sobre isso, ver PORTER, 1985.

${ }^{32}$ Yoneko IKEGAMI, 1905.

${ }^{33}$ Koto TAKAGAKI, 1899.
} 
Embora a casa fosse o lugar do parto, a população de shin-sanba aumentou a partir do final da década de 1890, quando sankai homens se aliaram na tarefa de modernizar as parteiras, e quando o Decreto das Parteiras de 1899 juntou as regulamentações locais. Curiosamente, o Decreto e os sankai formularam uma retórica que defendia a shin-sanba como a melhor assistente, enquanto outros tipos de parteiras, isto é, as kyû-sanba e as mumenkyo-sanba, seriam fenômenos apenas temporários, devendo ser expulsas do âmbito do novo parto medicalizado. Essa retórica, em cuja construção 'tanto' o sankai moderno 'quanto' as shin-sanba colaboraram, classificou parteiras com experiências diferentes, em ordem hierárquica.

Mesmo assim, a retórica era mera retórica. Na prática, as shin-sanba estavam - do mesmo modo que outros profissionais da saúde - à mercê de uma economia médica dominada pelo laissez-faire, na qual a prática freqüentemente entrava em choque com a boa retórica. Na verdade, as shin-sanba comumente se submetiam a outras parteiras, menos legitimadas, a fim de garantir uma carreira futura. Além disso, elas normalmente sucumbiam aos 'clientes', isto é, às parturientes e/ou, ainda com mais intensidade, a membros da família, que rejeitavam suas sugestões.

Essa situação continuou nos anos 1930, mas dinâmicas cada vez mais renovadas, claramente relacionadas ao nacionalismo, favoreceram as shin-sanba. ${ }^{34} \mathrm{Em} 1938$ foi criado - Ministério da Saúde e do Bem-Estar, e no alto de sua lista de prioridades estava o crescimento populacional e, portanto, as políticas de bem-estar de mães e crianças. Agentes de saúde entraram em contato com a Associação das Parteiras do Japão, e a Associação respondeu ao chamado do governo assumindo uma atitude de maior honradez e dignidade profissional. Ao mesmo tempo, o Josan no Shiori levou às últimas conseqüências o discurso político nacionalista, consolidando divisões de trabalho relativas à profissão e de gênero que os sankai modernos vinham propagando por décadas. Mais tarde, em 1941, quando o Ministério estabeleceu um novo esquema de qualificação para enfermeiras de saúde pública autônomas, muitas shin-sanba buscaram outra licença. Com duas licenças (sendo ambas reconhecidas), as shin-sanba eram capazes de expandir suas atribuições, o que lhes deu maiores chances de se estabelecer em suas regiões, como

\footnotetext{
${ }^{34}$ Sobre o fascismo e as trabalhadoras no Japão, ver, por exemplo, KENKYUKAI, 1982; e Mariko TAMANOI, 1998.
} 
profissionais da saúde e como trabalhadoras dedicadas à comunidade. De lá para cá, o tempo passou, as gerações se sucederam, e as 'velhas' parteiras foram sumindo aos poucos.

Tabela - Número de parteiras no Japão (1899-1943)

\begin{tabular}{|c|c|c|c|c|c|c|}
\hline Ano & $\begin{array}{c}\text { Aprovadas em } \\
\text { exames }\end{array}$ & $\begin{array}{l}\text { Com } \\
\text { experiência } \\
\text { prévia }\end{array}$ & $\begin{array}{l}\text { Com } \\
\text { atuação } \\
\text { restrita a } \\
\text { uma região }\end{array}$ & $\begin{array}{l}\text { Formada em } \\
\text { escolas creden- } \\
\text { ciadas }\end{array}$ & $\begin{array}{l}\text { Formadas em } \\
\text { escolas } \\
\text { estrangeiras }\end{array}$ & Total \\
\hline 1899 & 24 & 8.530 & 401 & - & - & 8.995 \\
\hline 1900 & 228 & 23.533 & 1.329 & - & - & 25.090 \\
\hline 1901 & 823 & 22.968 & 1.664 & - & - & 23.791 \\
\hline 1902 & 1.539 & 22.389 & 1.781 & - & - & 25.709 \\
\hline 1903 & 2.247 & 21.877 & 1.835 & - & - & 25.959 \\
\hline 1904 & 3.223 & 21.313 & 1.684 & - & - & 26.220 \\
\hline 1905 & 4.031 & 20.712 & 1.255 & - & - & 25.998 \\
\hline 1906 & 5.128 & 20.064 & 1.195 & - & - & 26.387 \\
\hline 1907 & 6.132 & 19.316 & 1.229 & - & - & 26.677 \\
\hline 1908 & 7.130 & 18.568 & 1.259 & - & - & 26.957 \\
\hline 1909 & 8.252 & 17.741 & 1.224 & - & - & 27.220 \\
\hline 1910 & 9.501 & 17.061 & 1.109 & - & - & 27.674 \\
\hline 1911 & 10.871 & 16.559 & 1.129 & - & - & 28.362 \\
\hline 1912 & 12.441 & 15.705 & 1.229 & - & - & 29.375 \\
\hline 1913 & 14.309 & 14.517 & 1.208 & - & - & 30.034 \\
\hline 1914 & 15.753 & 14.132 & 1.140 & 23 & - & 31.048 \\
\hline 1915 & 17.681 & 12.989 & 1.099 & 148 & - & 31.854 \\
\hline 1916 & 19.358 & 12.319 & 985 & 178 & - & 32.840 \\
\hline 1917 & 21.274 & 11.707 & 1.047 & 267 & - & 34.295 \\
\hline 1918 & 22.421 & 10.560 & 971 & 396 & - & 34.848 \\
\hline 1919 & 24.020 & 9.839 & 930 & 446 & - & 35.235 \\
\hline 1920 & 25.228 & 9.375 & 856 & 536 & - & 36.055 \\
\hline 1921 & 26.371 & 8.741 & 882 & 663 & - & 36.657 \\
\hline 1922 & 27.874 & 8.249 & 851 & 740 & - & 37.714 \\
\hline 1923 & 30.210 & 7.463 & 888 & 949 & - & 39.510 \\
\hline 1924 & 32.647 & 7.116 & 756 & 1.138 & - & 41.707 \\
\hline 1925 & 33.935 & 6.825 & 725 & 1.392 & - & 42.877 \\
\hline 1926 & 36.297 & 6.028 & 729 & 1.722 & - & 44.776 \\
\hline 1927 & 37.878 & 5.425 & 649 & 1.948 & - & 45.900 \\
\hline 1928 & 38.681 & 4.851 & 616 & 2.151 & - & 46.229 \\
\hline 1929 & 40.819 & 4.410 & 557 & 2.613 & - & 48.399 \\
\hline 1930 & 42.586 & 4.249 & 533 & 2.944 & - & 50.312 \\
\hline 1931 & 44.787 & 3.932 & 484 & 3.354 & - & 52.537 \\
\hline 1932 & 46.741 & 3.724 & 439 & 3.751 & - & 54.655 \\
\hline 1933 & 48.563 & 3.397 & 454 & 4.176 & - & 56.590 \\
\hline 1934 & 50.081 & 3.219 & 469 & 4.501 & - & 58.270 \\
\hline 1935 & 51.157 & 2.989 & 459 & 4.955 & - & 59.560 \\
\hline 1936 & 52.510 & 2.664 & 427 & 5.366 & - & 60.967 \\
\hline 1937 & 53.091 & 2.493 & 407 & 5.740 & 1 & 61.732 \\
\hline 1938 & 53.796 & 2.290 & 367 & 5.753 & 1 & 62.207 \\
\hline 1939 & 53.987 & 2.090 & 354 & 5.875 & 1 & 62.307 \\
\hline 1940 & 53.196 & 1.841 & 324 & 6.006 & 1 & 61.368 \\
\hline 1941 & 54.284 & 1.738 & 300 & 6.418 & 1 & 62.741 \\
\hline 1942 & 45.869 & 1.087 & 296 & 5.739 & - & 52.991 \\
\hline 1943 & 29.674 & 766 & 175 & 4.087 & 2 & 34.702 \\
\hline
\end{tabular}

Fonte: Okamoto Kiyoko. "Josanpu Katsudô no Rekishiteki Igi." Josanpu Zassi, v. 35, n. 8, 1981.p. 40. 


\section{Referências bibliográficas}

AllKUKAI, Onshi Zaidan Boshi (ed.). Nihon Saniku Shuzoku Shiryo Shusei. Tokyo: Daiichi Hoki Shuppan, 1977.

AKUSANBA NO SHOBATSU. Josan no Shiori, n. 47, p. 93-94. Apr. 1900.

BERNESTEIN, Gail Lee (ed.). Recreating Japanese Women, 1600-1945. California, Berkeley: California University Press, 1991.

BOWERZ, John Z. Western Medical Pioneers in Feudal Japan. Baltimore: Johns Hopkins Press, 1970.

BOWERZ, John Z. When the Twain Meet. Baltimore: Johns Hopkins University Press, 1980.

BUNBENJI SHUKKETSU NI YORU SHIBO. Josan no Shiori, n. 35, p. 113. Apr. 1899.

DAVIS-FLOYD, Robbie, and SARGENT, Carolyn (eds.). Childbirth and Authoritative Knowledge. Berkeley: University of California Press, 1997.

DONNISON, Jean. Midwives and Medical Men. A History of Inter-Professional Rivalries and Women's Rights. London: Heinemann, 1977.

EHRENREICH, Barbara, and ENGLISH, Deirdre. Witches, Midwives, and Nurses. A History of Women Healers. New York: The Feminist Press, 1973.

FUJIME, Yuki. Sei no Rekishigaku. Tokyo: Fuji Shuppan, 1998.

FUJIME, Yuki. "Aru Sanba no Kiseki: Shibahara Urako to sanji chosetsu." Nihonshi Kenky, n. 366, p. 90-112. Feb. 1993.

GARON, Sheldon. Molding Japanese Minds. The State in Everyday Life. New Jersey: Princeton University Press, 1997.

HASEGAWA, Hiroko. "Byoin-ka Izen no Osan." Shiso, n. 824, p. 72-106. 1993.

HUNTER, Janet (ed.). Japanese Women Working. London: Routledge, 1995.

IINKAI, Hensshû (ed.). Kôseishô 50 Nen-shi. Tokyo: Chuo Hoki Shuppan, 1988.

IKEGAMI, Yoneko. "37-nen Nikki no Ichi." Josan no Shiori, n. 107, p. 1416-1417. Apr. 1905.

ISHIZAKI, Shoko. "Meiji-ki no Seishoku wo Meguru Kokka Seisaku." Rekishi Hyoro, n. 600, p.3957, Apr. 2000.

ISHIZAKI, Shoko. "Nihon no Dataizai no Seiritsu." Rekishi Hyoron, n. 571, p.53-70. 1997.

KAMEYAMA, Michiko. Shinpan Kangogaku Zensho. Kangoshi, Tokyo: Mejikaru Furendo-sha, 1990. v. 6.

KATO, Chikako. "Senkanki ni okeru Joshi Rôdôsha to Rôdô Seisaku." In: OGUCHI, Yujiro (ed.). Onna no Shakaish. Tokyo: Shinano, 2001. p. 289-310.

KAWAHARA, Shinzo. "Kyûrai Sanba no Kiken." Josan no Shiori, n. 197, Oct. 1912. p. 963-964. KENKYUKAI, Joseishi Sougou (ed.). Nihon Joseishi. Tokyo: Tokyo Daigaku Shuppan, 1982. v. 5. KITOKU NO SANBA. Josan no Shiori, Sept. 1899. p. 238.

KUNIMOTO, Keikichi. San'iku-shi. Osan to Kosodate no Rekishi. Morioka: Morioka Taimusu, 1997.

LaFLEUR, William R. Liquid Life. Abortion and Buddhism in Japan. Princeton: Princeton University Press, 1992.

LITOFF, Judy Barrett. American Midwives, 1860 to the Present. Westport, Conn.: Greenwood Press, 1978.

MARLAND, Hilary, and RAFFERTY, Anne (eds.). Midwives, Society and Childbirth. Debates and Controversies in the Modern Period. London: Routledge, 1997.

MATSUOKA, Emiko. Shussan no Shakaijinruigaku. Tokyo: Kaimeisha, 1985.

NAGASAWA, Sumi. Sanba no Osumi-chan Ichidaiki. Tokyo: Soshisha, 1995.

NAKAMOTO, Atsuko. Kitto li Osan. Tokyo: Seiryû Shuppan, 1998.

NAMIHIRA, Emiko. Minzoku Shukyo Shiriizu. Kegare. Tokyo: Tokyodo Shuppan, 1985.

NEGISHI, Kennosuke. Iryo Minzokugakuron. Tokyo: Oyamakaku Shuppan, 1991. 
NISHIKAWA, Mugiko. Aru Kindai Sanba no Monogatari. Noto, Takeshima Mii no Katari yori. Tokyo: Midori no Yakata, 1989.

NISHIKAWA, Setsuko. Osan no Chie. Tókio: Kôdansha, 1992.

NOMOTO, Sumiko. Atatakai Osan. Josanpu Ichidaiki. Tokyo: Shobunsha, 1998.

OCHIAI, Emiko. "Aru Sanba no Nihon Kindai: Raihu hisutorii kara shakaishi e." In: OGINO, Miho et al. Seido Toshite no 'Onna'. Sei, San, Kazoku no Hikaku Shakaishi. Tokyo: Heibonsha, 1990. p. 257-322.

OGATA, Masakiyo. Nihon Sanka Gakushi. Tókio: Maruzen, 1919.

PORTER, Roy (ed). Patients and Practitioners. Lay Perceptions of Medicine in Pre-Industrial Society. Cambridge: Cambridge University Press, 1985.

PORTER, Roy. Health for Sale. Quackery in England, 1660-1850. Manchester: Manchester University Press, 1989.

ROUSSEAU, Julie. Enduring Labors. The 'New Midwife' and the Modern Culture of Childbearing in Early Twentieth Century Japan. (Unpublished Ph.D. Dissertation) Columbia University, 1998.

SAWAYAMA, Mikako. Shintai to Shussan No Kinsei. Tokyo: Keiso Shobo, 1999.

SHINMURA, Taku. Shussan to Seishokukan no Rekishi. Tokyo: Hosei Daigaku Shuppankyoku, 1996.

STEGER, Brigitte. "From impurity to Hyginene: the role of midwives in modernisation of Japan." Japan Forum, v. 6, n. 2, 1994. p. 175-184.

SUGAYA, Akira. Nihon Iryô Seido-shi. Tokyo: Hara Shobo, 1976. p. 295-304.

TAKAGAKI, Koto. "Santai Bunben no Ichirei." Josan no Shiori, n. 38, July 1899. p. 171-175.

TAKAHASHI, Aya. Western Influences on the Development of the Nursing Profession in Japan, 1868-1938. (Ph.D. Dissertation) University of London, 1999.

TAKEDA, Eiko. Ikusa Yu ni Inochi Sasaete. Okinawa-sen wo Ikita Josanpu no Kiroku. Tokyo: Domesu Shuppan, 1992.

TAMONOI, Mariko. Under the Shadow of Nationalism. Politics and Poetics of Rural Japanese Women. Honolulu: University of Hawaii Press, 1998.

TSURUMI, Patricia E. Factory Girls. Women in the Thread Mills of Meiji Japan. Princeton: Princeton University Press, 1990.

YOSHIMURA, Noriko. Kodomo wo Umu. Tokyo: Iwanami Shoten, 1996.

YUMOTO, Atsuko. Nagano-ken ni okeru Kindai Sanba no Kakuritsu Katei no Kenkyu. (Dissertation, Shinshû Daigaku, 1999). http://ehrlich.shinshu-u.ac.jp/tateiwa/2000/ 000300ya.htm. 1 Dec. 2000.

Tradução de Felipe Soares

\begin{abstract}
Modern Times, New Birth and New Midwives: Midwifery in Japan, 1868-1930s
Abstract: The shin-sanba, or medical 'new-midwife' who emerged during the Meiji period (18681912 ) in Japan seems, looked at from the present, to have successfully replaced the 'old-midwife' (kyû-sanba) and the increasingly criminalised 'non-licensed midwife' (mumenkyo-sanba), while midwifery was constantly developing as a modern medical profession. This paper suggests that the history of the midwife during the modern time was more complex than what we see today. First, the emergence and prosperity of shin-sanba were specific to the historical contingencies of modern Japan and the interplay of various groups of historical actors - hygiene officers, sankai (obstetrician-gynaecologists), other midwives, and 'clients'. Second, through the course of the modern period, shin-sanba did not replace other types of midwives and in fact, different kinds of midwives did coexist. Finally, the existence and status of midwives greatly depended upon the laissez faire medical market, and the market's realities often contradicted the medical rhetoric that favoured shin-sanba over other kinds of midwives.
\end{abstract}

Key words: midwives, Japan, Meiji period. 